\title{
STUDIES ON THE EFFECT OF TETRACYCLINE ON TRIGLYCERIDE SYNTHESIS IN EXPERIMENTAL RATS
}

\author{
Debesh Mukherjee and Supravat Mukherjee \\ Department of Applied Chemistry, University of Calcutta, India
}

(Received for publication December 4, 1968)

\begin{abstract}
1. Triglyceride synthesis in rat liver homogenate is stimulated by administration of a single therapeutic dose of tetracycline to the animal prior to sacrifice and maximum stimulation is observed 3 hours after drug-treatment.

2 . In the intact tetracycline-treated rat, incorporation of injected $1{ }^{14} \mathrm{C}-$ palmitate into liver triglyceride reaches its maximum 3 hours after the drug administration.

3. The release of newly synthesized triglyceride from liver to the circulation system seems to be impaired under the influence of the antibiotic treatment.

4. Tetracycline is unable to stimulate triglyceride synthesis in liver homogenate obtained from adrenalectomized rats treated with this antibiotic.
\end{abstract}

Tetracycline induced liver damage with fatty metamorphosis in human and experimental animal has already been reported ${ }^{1)}$. The antibiotic, when administered, was found to combine specifically with the mytochondria ${ }^{2)}$ and inhibit both oxidative phosphorylation and fatty acid oxidation ${ }^{3)}$. Rosen et al.4) reported that fatty liver caused by chlortetracycline in experimental animals was primarily of glyceride type; sex of the animals seemed not to influence the degree of fatty infiltration of the liver. HoRNING et $a l . .^{5}$ observed similar accumulation of triglyceride in the liver of rats. after carbon tetrachloride administration and the drug was found to be ineffective to induce such changes in adrenalectomized animals. Liver triglyceride is also elevated by stimulation of adrenal-pituitary axis. Though it was reported that tetracycline stimulates adrenal cortical activity ${ }^{6)}$, the part played by the adrenals to precipitate glycerides in the liver of rats due to tetracycline administration is not certain.

In the present study, triglyceride synthesis is investigated in liver homogenate and in the liver of intact rats, after giving a single therapeutic dose of tetracycline hydrochloride and the effect of this antibiotic on triglyceride synthesis in adrenalectomized animals is studied with tissues of the liver.

\section{Material and Methods}

Tetracycline hydrochloride was obtained from Standard Pharmaceuticals Ltd., Calcutta; adenosine triphosphate (ATP), reduced glutathione (GSH), niacinamide, coenzyme A (CoA) and reduced diphosphopyridine nucleotide $(\mathrm{NADH})$ were purchased from Sigma Chemicals Co., U.S.A.; silica gel G was obtained from E. Merck, West Germany and the radiochemicals were obtained from Radio Chemical Centre, Amersham, England.

Male albino rats weighing 100 120 g were kept on stock ration for a period of 4 weeks. Tetracycline hydrochloride in aqueous solution was administered intramuscularly to a group of rats at a dose level of $3.5 \mathrm{mg}$ per $100 \mathrm{~g}$ of body weight and the animals were sacrificed 
at 1-hour intervals after drug treatment was started. Livers were quickly excised, homogenized in Tris- $\mathrm{KCl}$ buffer ( $\mathrm{pH} 7.4$ ), and immediately incubated with potassium $1{ }^{14} \mathrm{C}-$ palmitate solution in a fully fortified medium ${ }^{7)}$ for 30 minutes at $37^{\circ} \mathrm{C}$ in Dubanoff shaker. The reaction was stopped by adding $0.5 \mathrm{ml}$ of $10 \%$ TCA. Total lipid content of the incubation medium was extracted three times with $25 \mathrm{ml}$ chloroform-methanol mixture. The solvent containing the lipid was evaporated and the last trace of solvent was removed under vacuum.

Triglyceride synthesis in liver-homogenate of adrenalectomized rats was studied following a single dose administration of the drug to the animal 3 hours before sacrifice. The rats were adrenalectomized under ether anaesthesia and kept on glucose-saline diet. After 2 days the animals were allowed to take stock ration along with normal saline for a period of 3 days before sacrifice.

Triglyceride synthesis in livers of control and tetracycline treated rats has been studied using intact animals in which albumin complex of $1{ }^{14} \mathrm{C}$-palmitate was injected in the tail-vein and quantity of labelled triglyceride in liver and serum was determined at different time intervals. The drug was administered 2 hours before palmitate injection and the animals were sacrificed at the interval of $15,30,60$ and 90 minutes after radio-palmitate administration. Livers and serum were saved and total lipid of the liver was extracted using the method followed by GERSHBEIN ${ }^{8)}$. Total lipid of the serum was extracted following the procedure of SPERRY and BRAND ${ }^{9}$.

Separation of triglyceride and phospholipid for assay of radio-activity was done using thin layer-chromatography ${ }^{10)}$ and all assessment of radio-activity was carried out in tracer lab Model SA-SC ISA super-scalar gas flow counter. Self absorption correction was made in all cases.

\section{Results and Discussion}

Following a single dose administration of tetracycline $(3.5 \mathrm{mg} / 100 \mathrm{~g})$ the conversion of $1-{ }^{14} \mathrm{C}$-palmitate to triglycerides in liver homogenates showed a marked rise over the rate in the control animals (Table 1). The maximum stimulation of liver triglyceride synthesis is obtained 3 hours after the drug treatment; thereafter the triglyceride radio-activity declines but the incorporation of palmitate radio-activity is still higher in livers of tetracycline-treated rats compared to the control animals at the conclusion of the experiment. A decreased incorporation of palmitate radio-activity in the phospholipid was observed under the conditions of the test. The experimental conditions outlined by STEIN et $a l^{7)}$ are optimal for triglyceride synthesis and the lower

Table 1. Effect of administration of a single dose of tetracycline on rates of synthesis of triglycerides in liver homogenates

\begin{tabular}{c|c|c|c}
\hline & $\begin{array}{c}\text { Time of sacrifice } \\
\text { after drug } \\
\text { administration }\end{array}$ & $\begin{array}{c}\text { Triglyceride radioactivity } \\
(\mathrm{cpm} / \mathrm{mg} \text { liver N) }\end{array}$ & $\begin{array}{c}\text { Phospholipid radioactivity } \\
\text { (cpm/mg liver N) }\end{array}$ \\
\hline Control & - & $10,450 \pm 1,086$ & $4,450 \pm 670$ \\
\hline Tetracycline-treated & 1 hour & $14,860 \pm 212$ & $4,550 \pm 260$ \\
& 2 hours & $19,000 \pm 300$ & $3,315 \pm 185$ \\
& 3 hours & $26,870 \pm 2,050$ & $1,980 \pm 270$ \\
& 4 hours & $18,350 \pm 1,010$ & $3,820 \pm 110$ \\
\hline
\end{tabular}

Ten animals were used for each experiment; duplicate incubation with liver homogenates from each rat.

Each incubation flask contained : $10 \mu$ moles $\mathrm{K}-\alpha$ glycerophosphate, $10 \mu$ moles ATP, $10 \mu$ moles $\mathrm{MgCl}_{2}, \quad 2.5$ umoles $\beta$-mercaptoethanol, $0.5 \mathrm{ml}$ liver homogenate, 0.1 mole of $1-14 \mathrm{C}$-palmitate (1.1 $\times 10^{5} \mathrm{cpm}$ ), K-phosphate buffer $20 \mu$ moles. $2.5 \mathrm{ml}$ with $\mathrm{KCl}$-Tris buffer (pH 7.4) 
Table 2. Liver and serum triglyceride radioactivity of control and tetracycline-treated rats following in vivo administration of $1{ }^{14} \mathrm{C}$-Palmitate by the tail-vein

\begin{tabular}{|c|c|c|c|c|c|}
\hline \multirow{2}{*}{$\begin{array}{l}\text { Time after } \\
\text { palmitate } \\
\text { administered }\end{array}$} & \multirow{2}{*}{$\begin{array}{l}\text { No. of } \\
\text { rats }\end{array}$} & \multicolumn{2}{|c|}{$\begin{array}{l}\text { Liver } \\
\text { (Total counts in triglycerides per } g \\
\text { of liver) } \pm \text { S. D. }\end{array}$} & \multicolumn{2}{|c|}{ 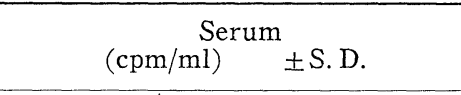 } \\
\hline & & Control & Tetracycline-treated & Control & Tetracycline-treated \\
\hline 15 minutes & 6 & $23,525 \pm 2,385$ & $41,325 \pm 1,616$ & $2,095 \pm 35$ & $1,755 \pm 154$ \\
\hline 30 minutes & 6 & $21,805 \pm 2,414$ & $47,430 \pm 3,564$ & $2,395 \pm 65$ & $1,180 \pm 27$ \\
\hline 60 minutes & 6 & $16,760 \pm$ & $48,570 \pm 1,872$ & $2,235 \pm 55$ & $1,215 \pm 142$ \\
\hline 90 minutes & 6 & $9,287 \pm$ & $20,260 \pm 2,888$ & $1,760 \pm 68$ & $1,105 \pm 94$ \\
\hline
\end{tabular}

$1-{ }^{14} \mathrm{C}$-Palmitate $\left(1.8 \times 10^{6} \mathrm{cpm} / 100 \mathrm{~g}\right.$ body weight $)$ was administered as albumin complex to each rat through the tail-vein 3 hours after administration of $3.5 \mathrm{mg}$ tetracycline per $100 \mathrm{~g}$ of body weight of rat. Duplicate aliquots of lipid extract from each sample were used for thin-layer chromatographic separation of triglycerides.

incorporation of $1{ }^{14} \mathrm{C}$-palmitate in liver phospholipids in these in vitro experiments may not represent the true rates of phospholipid synthesis in the intact animal.

It is evident from the results of in vivo experiments (Teble 2) that in control animal, maximum radio-activity in liver triglycerides is observed 15 minutes after $1-{ }^{14} \mathrm{C}$-palmitate administration. After that, the radio-isotope level in liver triglyceride fraction begins to fall and 15 minutes later approximately $10 \%$ decrease in liver triglyceride radio-activity is observed. Ninety minutes after administration about $70 \%$ radio-activity has disappeared. In tetracycline-treated animals incorporation of intravenously administered radio-palmitate into liver-triglycerides is much higher in comparison to the control animals and the level of triglyceride radio-activity at various time intervals remains significantly elevated, although 90 minutes after administration the level of radio-isotope is approximately $50 \%$ lower than that observed 15 minutes after palmitate injection. Furthermore, while triglyceride radio-activity begins to decrease within 30 minutes in the control group, triglyceride radio-activity in livers of drug-treated animals still increases even 60 minutes after radio-palmitate administration. In the control group, the observed decline in liver triglyceride activity is reflected in the palmitate specific activity of serum triglycerides, indicating rapid release of newly synthesized triglycerides from the liver to the circulation system. The serum triglyceride radio-activity rises to a maximum approximately $30 \sim 45$ minutes after palmitate administration, whereas the radio-activity of liver triglyceride of controls shows a peak value at 15 minutes. The liver triglyceride radio-activity of rats pre-treated with tetracycline is maintained at a higher level for a longer time and the percentage of labelled triglyceride appearing in the serum is lower than the corresponding value in control-animals. While the incorporation in serum triglycerides increases subsequently in controls, one observes a decline in triglyceride specific activity in serum of drug-treated rats. This decreased radio-activity in serum triglyceride of drug-treated animals may be due to impaired release of newly synthesized liver triglycerides to serum. However, a drop in liver triglyceride radio-activity 90 minutes after radio-palmitate injection was observed in drug-treated rats. This may implicate that release of triglycerides from liver to serum must necessarily take place, although the rate of release of liver triglycerides in tetracycline-treated rats is far slower than the release observed in control rats. 
The results of triglyceride synthesis in adrenalectomized rats after administration of tetracycline are presented in Table 3. It is evident from the study that triglyceride synthesis in the liver is considerably reduced due to adrenalectomy and tetracycline is unable to stimulate the triglyceride synthesis in livers of adrenalectomized animals. This inability of tetracycline to induce increased triglyceride synthesis in liver of adrenalectomized rats may, therefore, indicate that tetracycline stimulates triglyceride synthesis via an action on the adrenal gland.

\section{References}

1) Moser, H. R. : Reactions to tetracyclines. Clin. Pharma. Therap. $7: 117 \sim 132,1966$

2) Du Buy, H. G. \& J. L. Showacre : Selective localization of tetracycline in mitochondria of living cells. Science $133: 196 \sim 197,1961$

3) Brody, T. M. \& J. A. BaIn : Effect of Aureomycin and Terramycin on oxidative phosphorylation (Abst.). J. Pharmacol. \& Exper. Therap. $103: 338,1951$

4) Rosen, H.; A. Einheber, N. D. Brown \& R. E. Wren : Chlortetracycline and mouse intestinal wall. Nature $214: 671 \sim 674,1967$

5) Horning, M. G.; M. Wakabayashi \& H. M. Maling: In effects of drugs on synthesis and mobilisation of lipids. Horning E. C. ed. Pergamon Press, U.S.A. 1963.

6) Trams, E. G.; H. K. Kashiwa, I. Cornman \& C. T. Klopp : Effects of large doses parenterally injected chlortetracycline on adrenal glands of rats. Antibiotic Med. $1: 677 \sim 688,1955$

7) Stein, Y. \& B. Shapiro : Syntehsis of neutral glycerides by fractions of rat liver homogenate. Biochem. Biophys. Acta $24: 197 \sim 201,1957$

8) Gershbein, L. L. : Antibiotics and liver regeneration in rats. J. Antibiotics $20: 25 \sim 29,1967$

9) Sperry, W. M. \& F. C. Brand : Determination of total lipids in blood serum. J. Biol. Chem. $213: 69 \sim 72,1955$

10) Levin, E. \& C. Head : Quantitative analysis of tissue lipids by thin-layer chromatography. Anal. Biochem. $10: 23 \sim 27,1965$ 